\title{
Studi Korelasi antara Pendidikan dan Pelatihan (Diklat) Tutor PAUD dengan Peningkatan Kompetensi Mengajar
}

\author{
Syanjar Sya'i, M. A. Rizka*, I Made Gunawan \\ Fakultas Ilmu Pendidikan dan Psikologi UNDIKMA \\ *Corresponding Author. Email: m.ariefrizka@undikma.ac.id
}

\begin{abstract}
The purpose of this study was to analyze the correlation between education and training (Diklat) of PAUD tutors with increasing teaching competence. This research method uses the correlational method. The sample in this study were 20 PAUD tutors at BPKBM NTB. The instruments used in this research are questionnaires and documentation. The analysis technique used is product moment correlation analysis. The results showed the arithmetic $r$ value of 0.455 while the value of $\mathrm{r}$ in the table with a significance level of $5 \%$ and $\mathrm{N}=$ 20 was 0.444 ( $\mathrm{r}$ count $0.455>\mathrm{r}$ table 0.444 ). This means that Ho is rejected while $\mathrm{Ha}$ is accepted. Based on the interpretation table of the correlation coefficient, it can be seen that the correlation $r$ count is 0.455 including the medium category. The conclusion obtained from the results of this study is that there is a positive correlation between education and training (DIKLAT) with an increase in the teaching competence of PAUD tutors.
\end{abstract}

\begin{abstract}
Abstrak: Tujuan dari penelitian ini adalah untuk menganalisis korelasi antara pendidikan dan pelatihan (Diklat) Tutor PAUD dengan peningkatan kompetensi mengajar. Metode penelitian ini menggunakan metode korelasional. Sampel dalam penelitian ini berjumlah 20 orang Tutor PAUD di BPKBM NTB. Instrumen yang digunakan dalam penelitian ini yaitu angket dan dokumentasi. Teknik analisis yang digunakan adalah analisis korelasi product moment. Hasil penelitian menunjukkan nilai $r$ hitung sebesar 0,455 sedangkan nilai $r$ dalam tabel dengan taraf signifikasi 5\% dan $\mathrm{N}=20$ adalah 0,444( $\mathrm{r}$ hitung 0,455 > r tabel 0,444). Hal ini berarti Ho ditolak sedangkan Ha diterima. Berdasarkan tabel interprestasi koefisien korelasi dapat diketahui bahwa korelasi $r$ hitung sebesar 0,455 termasuk kategori yang sedang. Kesimpulan yang diperoleh dari hasil penelitian ini adalah terdapat korelasi yang positif antara pendidikan dan pelatihan (DIKLAT) dengan peningkatan kompetensi mengajar Tutor PAUD.
\end{abstract}

\author{
Article History \\ Received: 25-03-2021 \\ Revised: 10-04-2021 \\ Accepted: 24-04-2021 \\ Published: 07-07-2021
}

\section{Key Words:}

Education and Training, Teaching Competence, PAUD.

\section{Sejarah Artikel}

Diterima: 25-03-2021

Direvisi: 10-04-2021

Disetujui: 24-04-2021

Diterbitkan: 07-07-2021

\section{Kata Kunci:}

Pendidikan dan Pelatihan,

Kompetensi Mengajar,

PAUD.

How to Cite: Sya'i, S., Rizka, M., \& Gunawan, I. (2021). Studi Korelasi Antara Pendidikan dan Pelatihan (Diklat) Tutor PAUD dengan Peningkatan Kompetensi Mengajar. Jurnal Paedagogy, 8(3), 351-356. doi:https://doi.org/10.33394/jp.v8i3.3793

d. https://doi.org/10.33394/jp.v8i3.3793

This is an open-access article under the CC-BY-SA License.

\section{Pendahuluan}

Pendidikan Anak Usia Dini (PAUD) dalam UU Nomor 20 Tahun 2003 tentang Sistem Pendidikan Nasional meliputi PAUD formal dan nonformal, dimana kedua jenis PAUD tersebut tentunya saling melengkapi dan menguatkan satu sama lain dalam rangka memberikan akses PAUD yang bermutu dan mampu menjangkau sampai ke pelosok desa. Dewasa ini kesadaran masayarakat akan pentingnya pendidikan anak usia dini (PAUD) semakin tinggi, ditandai dengan maraknya pendirian lembaga PAUD di berbagai tempat. Hal ini tentu dimaknai secara positif (Sri et al., 2018).

Sebagaimana yang tercantum dalam PP Nomor 19 Tahun 2005 tentang Standar Nasional Pendidikan pada standar pendidik disini disebutkan bahwa seseorang pendidik PAUD minimal pendidikan SI/D IV PAUD/Psikologi. Untuk memenuhi standar tersebut tentunya cukup berat, artinya memerlukan upaya yang kuat dari semua pihak, salah satunya 
adalah dengan memfasilitasi kegiataan peningkatan mutu berbentuk pendidikan dan pelatihan bagi para tutor atau pendidik PAUD. Pendidikan dan pelatihan yang ditempuh oleh pendidik PAUD untuk meningkatkan kompetensinya bisa melalui seminar, workshop serta pendidikan dan pelatihan kompetensi. Seminar merupakan suatu pertemuan sekelompok orang yang diselenggarakan untuk dapat membahas suatu masalah serta mencari solusi ilmiah terhadap permasalahan tersebut (Ibeng, 2020). Sedangkan workshop adalah suatu kegiatan dimana beberapa orang yang ahli di bidang tertentu berkumpul dengan sekelompok orang dengan latar belakang profesi yang sama dan melakukan interaksi satu sama lain untuk membahas masalah tertentu (maxmanroe.com, n.d. dalam Isnaini et al., 2020). Untuk meningkatkan kualitas kemampuan yang menyangkut kemampuan kerja, berpikir dan keterampilan maka pendidikan dan pelatihan yang paling penting diperlukan (Hidayat \& Nurasyiah, 2017). Dengan kata lain pentingnya pendidikan dan pelatihan (Diklat) dalam organisasi adalah perbaikan kinerja pegawai yang meliputi pengetahuan, sikap, dan keterampilan yang mendukung setiap para pegawai sesuai yang diinginkan oleh lembaga (Pakpahan, Siswidiyanto, \& Sukanto, 2014).

Permasalahan yang ada di lapangan bahwa dibalik berkembangnya lembaga-lembaga PAUD tersebut ternyata masih banyak yang menyimpan masalah baik dalam hal sarana, prasarana, kualifikasi pendidik maupun manajemen pengelolaan. Layanan PAUD yang berkualitas merupakan kebutuhan yang harus dipenuhi oleh setiap penyelenggaraan pendidikan. Banyak faktor yang perlu diperhatikan dalam upaya mewujudkan layanan PAUD yang berkualitas, salah satunya adalah dukungan ketersediaan Tutor atau pendidik professional yang memiliki keterampilan mengajar yang baik. PAUD yang bermutu, memiliki tutor yang mampu menguasai kompetensi terhadap tugas dan fungsi dalam pembelajaran di PAUD. Adapun tujuan penelitian ini adalah untuk menganalisis korelasi antara pendidikan dan pelatihan (diklat) tutor PAUD dengan peningkatan kompetensi mengajar di BPKBM NTB.

\section{Metode Penelitian}

Metode penelitian ini menggunakan metode korelasional dengan pendekatan kuantitatif. Dalam penelitian ini tidak menggunakan sampel, tetapi menggunakan studi populasi karena peserta pelatihan tersebut kurang dari 100 orang yaitu hanya berjumlah 20 orang. Instrumen penelitian adalah suatu alat yang digunakan mengukur fenomena alam maupun sosial yang diamati (Sugiyono, 2014; Arikunto, 2010; Sumiyanty et al., 2018). Instrumen yang digunakan dalam penelitian ini adalah angket dan dokumentasi. Sedangkan teknik analisis data penelitian ini menggunakan analisis korelasi product moment.

\section{Hasil Penelitian dan Pembahasan}

Data yang diperoleh dalam penelitian ini berupa data hasil angket tentang korelasi antara pendidikan dan pelatihan (diklat) tutor PAUD dengan peningkatan kompetensi mengajar di BPKBM NTB. Adapun langkah- langkah yang ditempuh pada penelitian ini adalah (1) Merumuskan hipotesisnol (Ho), (2) Menyusun tabel kerja, (3) Memasukkan data kedalam rumus, (4) Pengujian nilai $r$ Product Moment, (5) Menarik kesimpulan.

\section{Merumuskan Hipotesis Nol (Ho)}

Hipotesis yang diajukan dalam penelitian ini adalah Hipotesis alternatif (Ha) yaitu : terdapat korelasi antara pendidikan dan pelatihan (diklat) tutor PAUD dengan peningkatan kompetensi mengajar di BPKBM NTB. Selain hipotesis alternatif (Ha) yang telah diajukan dalam penelitian ini sebelumnya, maka pada analisis data dapat diubah menjadi hipotesis nol 
(Ho) pada penelitian ini adalah tidak ada korelasi antara pendidikan dan pelatihan (diklat) tutor PAUD dengan peningkatan kompetensi mengajar di BPKBM NTB.

Menyusun tabel kerja

Tabel kerja merupakan tabel untuk mengolah data yang telah dikumpulkan dengan metode angket guna menguji hipotesis nilai tentang korelasi antara pendidikan dan pelatihan (diklat) tutor PAUD dengan peningkatan kompetensi mengajar di BPKBM NTB. Adapun tabel kerja dalam penelitian ini adalah sebagai berikut :

Tabel 1.Tabel Kerja Uji Hipotesis

\begin{tabular}{|c|l|c|c|c|c|c|}
\hline No & \multicolumn{1}{|c|}{ Nama } & X & Y & $\mathbf{X}^{\mathbf{2}}$ & $\mathbf{Y}^{\mathbf{2}}$ & $\mathbf{X Y}$ \\
\hline 1 & Jaeni, S.Pd & 53 & 53 & 2809 & 2809 & 2809 \\
\hline 2 & Nurhayati, S.Pd & 49 & 50 & 2401 & 2500 & 2450 \\
\hline 3 & Sri Nurmala, S.Pd & 48 & 49 & 2304 & 2401 & 2352 \\
\hline 4 & Serianti, S.Pd & 49 & 54 & 2401 & 2916 & 2646 \\
\hline 5 & Khairunniswati & 49 & 47 & 2401 & 2209 & 2303 \\
\hline 6 & Juairiah & 54 & 52 & 2916 & 2704 & 2808 \\
\hline 7 & Zurriyatun Solihah, S.Pdi & 55 & 52 & 3025 & 2704 & 2860 \\
\hline 8 & Hisniati, S.Pd & 55 & 56 & 3025 & 3136 & 3080 \\
\hline 9 & Dra. Husnul Hatimah & 58 & 53 & 3364 & 2809 & 3074 \\
\hline 10 & Siti Raihanun, S.Pd & 53 & 60 & 2809 & 3600 & 3180 \\
\hline 11 & Siti Maryam, S.Pd & 54 & 53 & 2916 & 2809 & 2862 \\
\hline 12 & B. Iriantini, S.Pd & 57 & 54 & 3249 & 2916 & 3078 \\
\hline 13 & Nopia Hasri, S.Pd & 53 & 50 & 2809 & 2500 & 2650 \\
\hline 14 & Annisa Rahmawati, S.Pd & 62 & 60 & 3844 & 3600 & 3720 \\
\hline 15 & Hilmiah, S.Pd & 53 & 51 & 2809 & 2601 & 2703 \\
\hline 16 & Wati Susilawati & 57 & 56 & 3249 & 3136 & 3192 \\
\hline 17 & Nurul Muhajirah & 56 & 49 & 3136 & 2401 & 2744 \\
\hline 18 & Rusmini, S.Pd & 49 & 56 & 2401 & 3136 & 2744 \\
\hline 19 & Mitahul Jannah, S.Pd & 55 & 53 & 3025 & 2809 & 2915 \\
\hline 20 & M.Jamil, S.Pd & 1072 & 1055 & 57702 & 55905 & 56661 \\
\hline & & & & & \\
\hline
\end{tabular}

Memasukkan data kedalam rumus

Berdasarkan tabel kerja diatas, maka langkah selanjutnya adalah memasukkan data kedalam rumus sebagai berikut:

$$
\begin{array}{ll}
\Sigma=1072 & \Sigma Y=56661 \\
\Sigma Y=1055 & (\Sigma)^{2}=1149184 \\
\Sigma^{2}=57702 & (\Sigma Y)^{2}=1113025 \\
\Sigma Y^{2}=55905 & N=20
\end{array}
$$




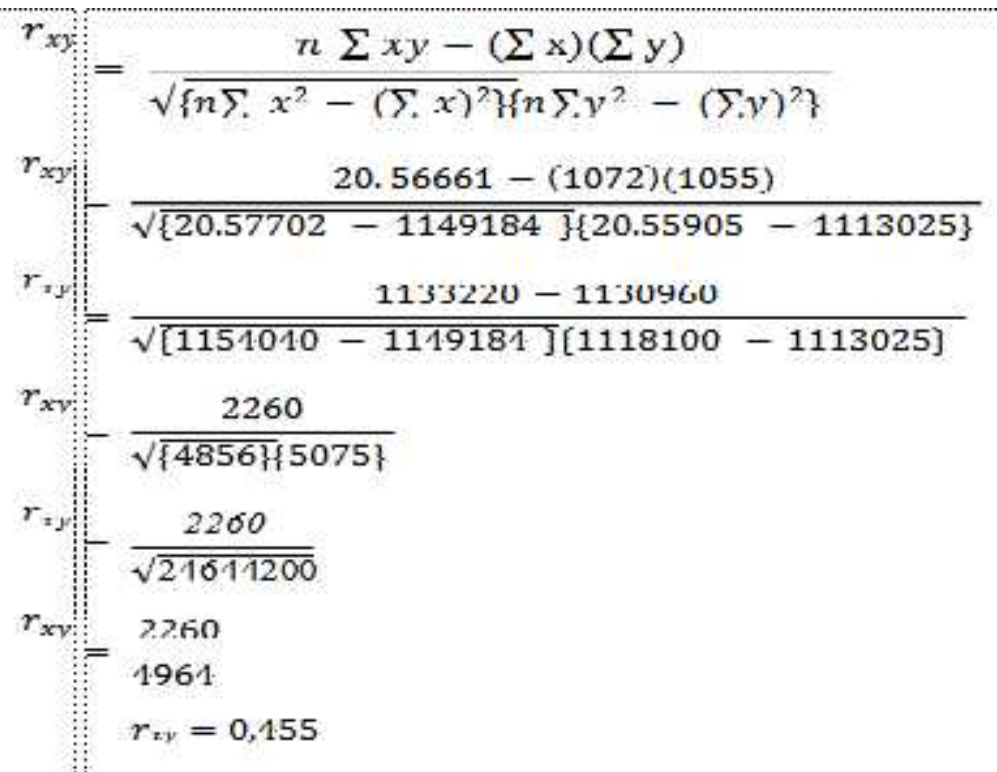

Dalam penelitian ini, ditemukan nilai $r$ hitung yaitu 0,455 dimana nilai $r$ product moment pada tabel dengan taraf signifikasi $5 \%$ dan $\mathrm{N}=20$ yaitu 0,444 . Hal ini menunjukkan bahwa nilai $r$ hitung lebih besar daripada nilai $r$ product moment pada tabel $(0,455>0,444)$.

\section{Menguji nilai $r$ Product Moment}

Hasil penelitian $r_{x y}$ yang diperoleh dalam penelitian ini adalah 0,455 dimana nilai $r$ product moment pada tabel dengan taraf signifikasi5\% dan $\mathrm{N}=20$ yaitu 0,444 . Kenyataan ini menunjukkan bahwa nilai $r$ hitung lebih besar daripada nilai $r$ product moment dalam tabel $(0,455>0,444)$. Dengan demikian Hipotesis nol (Ho) "ditolak" dan Hipotesis alternatif (Ha) "diterima".

\section{Menarik kesimpulan}

Hasil analisis data menunjukkan bahwa nilai $r$ hitung lebih besar dari pada nilai $r$ product moment dalam tabel $(0,455>0,444)$, maka kesimpulan dari penelitian ini menunjukkan bahwa terdapat korelasi antara pendidikan dan pelatihan (diklat) tutor PAUD dengan peningkatan kompetensi mengajar di BPKBM NTB. Adapun tingkat intreprestasi nilai koefisien : terdapat korelasi antara pendidikan dan pelatihan (diklat) tutor PAUD dengan peningkatan kompetensi mengajar di BPKBM NTB.dapat dilihat dalam tabel sebagai berikut:

\section{Tabel 2. Intreprestasi Nilai Koefisien Korelasi}

\begin{tabular}{|c|c|}
\hline Interval Koefisien & Tingkat Hubungan \\
\hline $0,00-0,1999$ & Sangat Rendah \\
$0,20-0,399$ & Rendah \\
$0,40-0,599$ & Sedang \\
$0,60-0,799$ & Kuat \\
$0,80-1,000$ & Sangat Kuat \\
\hline
\end{tabular}

(Sugiyono, 2014)

Dari tabel diatas dapat disimpulkan bahwa korelasi antara pendidikan dan pelatihan (diklat) tutor PAUD dengan peningkatan kompetensi mengajar di BPKBM NTB menunjukkan hubungan yang "sedang". Dari hasil analisis data penelitian menunjukkan bahwa nilai $r$ hitung lebih besar dari pada nilai $r$ tabel $(0,455>0,444)$. Maka Hipotesis alternatif $(\mathrm{Ha})$ yang diajukan diterima dan Hipotesis nol (Ho) ditolak, artinya penelitian ini adalah positif, 
yakni terdapat korelasi antara pendidikan dan pelatihan (diklat) tutor PAUD dengan peningkatan kompetensi mengajar di BPKBM NTB.

Penyelenggaran pendidikan dan pelatihan (Diklat) merupakan salah satu upaya untuk meningkatkan kualitas tutor PAUD sesuai dengan kebutuhan pekerjaannya yang dalam hal ini keterampilan mengajar baik di kelas maupun luar kelas. Dalam rangka meningkatkan mutu pendidik pada setiap unit kerja juga akan berhubungan dengan hakikat pendidikan dan pelatihan. Adapun hasil penelitian ini sesuai dengan hasil penelitian yang dilakukan oleh Isnaini, F. Z., Siwiyanti, L., \& Hurri, H. I. (2020) yang menyimpulkan bahwa pendidikan dan pelatihan memiliki pengaruh dalam peningkatan kompetensi profesional pendidik PAUD di Kota Sukabumi. Disamping itu hasil penelitian ini juga memperkuat teori bahwa pendidikan dan pelatihan merupakan salah satu faktor yang penting dalam pengembangan SDM. Pendidikan dan pelatihan bertujuan agar dapat meningkatkan pengetahuan, keterampilan bekerja dan sikap untuk dapat melaksanakan tugas jabatan secara operasional dengan didasari kepribadian etika, peningkatan efesiensi, efektivitas, serta kualitas pelaksanaan tugas yang dilakukan dengan semangat kerjasama dan tanggung jawab sesuai dengan lingkungan kerja dan organisasi, dengan demikian dapat meningkatkan produktivitas kerja.

Berdasarkan hasil nilai koefisien data penelitian ini diperoleh nilai $r$ hitung lebih besar dari nilai $r$ tabel $(0,455>0,444)$, maka dapat disimpulkan bahwa terdapat korelasi antara pendidikan dan pelatihan (diklat) tutor PAUD dengan peningkatan kompetensi mengajar di BPKBM NTB. Sesuai dengan hasil penelitian yang telah dilaksanakan bahwa diklat Tutor PAUD sangat perlu dilaksanakan karena melalui diklat ini Tutor PAUD dapat memiliki kompetensi yang tinggi terhadap tugas dan fungsi dalam peningkatan kompetensi mengajar di PAUD.

\section{Kesimpulan}

Kesimpulan yang diperoleh dari hasil penelitian ini bahwa nilai $r$ hitung sebesar 0,455 sedangkan nilai $r$ dalam tabel dengan taraf signifikasi 5\% dan $\mathrm{N}=20$ adalah 0,444(r hitung $0,455>r$ tabel 0,444). Hal ini berarti Ho ditolak sedangkan Ha diterima. Berdasarkan tabel interprestasi koefisien korelasi dapat diketahui bahwa korelasi $r$ hitung sebesar 0,455 termasuk kategori yang sedang. Sehingga kesimpulan yang diperoleh dari hasil penelitian ini adalah terdapat korelasi yang positif antara pendidikan dan pelatihan (DIKLAT) dengan peningkatan kompetensi mengajar Tutor PAUD.

\section{Saran}

Saran yang disampaikan berdasarkan hasil penelitian ini adalah; (1) Bagi Kepala BPKBM NTB diharapkan agar tetap mempertahankan program Pendidikan dan Pelatihan Tutor PAUD yang sangat dibutuhkan oleh Pendidik atau Tutor PAUD dalam upaya meningkatkan kompetensi mengajar Tutor di PAUD serta mewujudkan layanan PAUD yang berkualitas. (2) Bagi Tutor PAUD diharapkan agar mempertahankan kompetensi mengajaryang dimilikinya sehingga hasil yang dicapai tetap maksimal.

\section{Daftar Pustaka}

Arikunto, Suharsimi, (2010). Prosedur Penelitian Suatu Pendekatan Praktek. Jakarta: Rineka Cipta

Arsyad Ahmad. (2007). Pendidikan Anak Dini Usia. Bandung: CV. Alfabeta. 
Hidayat, \& Nurasyiah. (2017). Pengaruh Diklat (Pendidikan Dan Pelatihan) Terhadap Prestasi Kerja Karyawan Di Bank Bpr Rokan Hulu. Jurnal Ilmiah Cano Ekonomos, 6.

Ibeng, P. (2020). Pengertian Seminar. Retrieved from Pengertian Seminar

Isnaini, F. Z., Siwiyanti, L., \& Hurri, H. I. (2020). ANALISIS PENDIDIKAN DAN PELATIHAN DALAM PENINGKATAN KOMPETENSI PROFESIONAL PENDIDIK PAUD DI KOTA SUKABUMI. utile: Jurnal Kependidikan, 6(2), 200209.

Kamil, Mustofa. 2007. Model Pendidikan Dan Pelatihan. Bandung: CV. Alfabeta

Marzuki, M.S. 1992. Strategi dan Model Pelatihan. Malang: IKIP Malang Mutmainnah, Nurul. Skripsi, 2017. Hubungan Antara Kompetensi Tutor Dengan Motivasi Belajar Warga Belar Pendidikan Kesetaraan Paket C di PKBMCeria di Desa Sesela Kabupaten Lombok Barat. Mataram

Pakpahan, E. S., Siswidiyanto, \& Sukanto. (2014). Pengaruh Pendidikan Dan Pelatihan Terhadap Kinerja Pegawai. Administrasi Publik, 2

Rasyad, Ach. 2014. Pendidikan dan Pelatihan Dalam Pemberdayaan Masyarakat Elang Emas

Sri, S. N., Rizka, M. A., \& Maskun, M. (2018). Pengaruh Pelatihan Hypnoparenting Terhadap Peningkatan Pemahaman Orang Tua dalam Mendidik Anak Usia Dini di Desa Aikmual Kabupaten Lombok Tengah Tahun 2016. Transformasi: Jurnal Penelitian dan Pengembangan Pendidikan Non Formal Informal, 3(1).

Sugiyono, (2014). Metode Penelitian Pendidikan (Pendekatan Kuantitatif, Kualitatif, dan $R \& D)$. Bandung: CV. Alfabeta.

Sujino, Yuliani. N. 2013. Konsep Dasar Pendidikan Anak Usia Dini. Jakarta: PT Indeks

Sulistyo, Arif https://wordpress.com/jurusan-pls/pengertian-paud./Diakses pada tanggal 01/09/2016, Pukul: 14.05 Wita

Sumiyanty, E. S. E., Suharyani, S. S., \& Rizka, M. A. R. M. A. (2018). HUBUNGAN PROGRAM TAMAN BACAAN MASYARAKAT (TBM) TERHADAP MINAT MEMBACA WARGA BELAJAR KEAKSARAAN FUNGSIONAL DI PKBM CERIA. Transformasi: Jurnal Penelitian dan Pengembangan Pendidikan Non Formal Informal, 4(1).

Suryabrata. Sumadi. 2010. Metodologi Penelitian. Jakarta: Raja Grafindo Persada

Undang-Undang Republik Indonesia Nomor 20 Tahun 2003. Sistem Pendidikan Nasional. Jakarta: Departemen Pendidikan Nasional Republik Indonesia 